\title{
DENSITAS TANGKASI (Tarsius spectrum) PADA ELEVASI YANG BERBEDA DI GUNUNG KLABAT, MINAHASA UTARA
}

\author{
Mylton Mantouw $^{1)}$, Saroyo ${ }^{1)}$, Rooije R.H. Rumende ${ }^{1)}$, Roni Koneri ${ }^{1)}$ \\ 1)Jurusan Biologi, FMIPA, Universitas Sam Ratulangi, Manado \\ e-mail: mylton_mantouw@yahoo.com; yoyoksumarto@gmail.com; rooije.rumende@yahoo.com; \\ ronicaniago@yahoo.com
}

\begin{abstract}
ABSTRAK
Tarsius spectrum (nama sinonim: Tarsius tarsier) dalam bahasa lokal disebut tangkasi (Minahasa), ngasi (Sulawesi Tengah), Tanda bona passo (Wana), Podi (Tolaki), Wengu (Mornene) merupakan spesies primata endemik Sulawesi. Tangkasi merupakan salah satu primata terkecil dan beberapa diantara anggota spesiesnya merupakan satwa endemik Sulawesi yang terancam punah dan dilindungi. Menurut IUCN (2008), tarsius dalam Red Data Book IUCN (International Union for Conservation of Nature and Natural Resources) termasuk dalam kategori vulnerable (rentan). Penelitian ini bertujuan untuk menghitung densitas tangkasi pada elevasi yang berbeda di Gunung Klabat, Minahasa Utara. Metode yang dilakukan dalam penelitian ini ialah estimasi densitas Tangkasi berdasarkan vokalisasi (duet call) sesuai dengan yang dikembangkan oleh Saroyo et al (2014). Pada setiap elevasi dibuat 10 plot yang berbentuk lingkaran dengan diameter $100 \mathrm{~m}$. Jarak antar plot $200 \mathrm{~m}$. Berdasarkan hasil pengamatan, densitas tangkasi pada elevasi $500 \mathrm{mdpl}(2,04 \mathrm{individu} / \mathrm{Ha})$, elevasi $1000 \mathrm{mdpl}(2,68 \mathrm{individu} / \mathrm{Ha})$, elevasi $1500 \mathrm{mdpl}(0,89 \mathrm{individu} / \mathrm{Ha})$ dan elevasi $2000 \mathrm{mdpl}$ (0,12 individu/Ha).
\end{abstract}

Kata Kunci : Densitas, Tarsius spectrum, Gunung Klabat, Minahasa Utara

\section{DENSITY OF TANGKASI (Tarsius spectrum) AT DIFFERENT ELEVATIONS IN THE MOUNTAINS CLABAT, NORTH MINAHASA}

\begin{abstract}
Tarsius spectrum (synonym: Tarsius tarsier) in local language called tangkasi (Minahasa), ngasi (Central Sulawesi), Tanda bona passo (Wana), Podi (Tolaki), Wengu (Mornene) is a primate species endemic of Sulawesi. Tangkasi is one of the smallest primates and some of them the members of species is a species endemic to Sulawesi and protected. According to IUCN (2008), tarsius in the Red Data Book of IUCN (International Union for Conservation of Nature and Natural Resources) are included in the category of vulnerable. The objective of this research is quantify the density tangkasi at different elevations in Klabat, North Minahasa. The method of this research is to estimate the density of Tangkasi based duet call that suit with that developed by Saroyo et al (2014). At each elevation has made 10 plots were in circle form with diameter of 100 $\mathrm{m}$. The distance between the plot are $200 \mathrm{~m}$. Based on the observations, the tangkasi density at elevation of 500 meters above the sea (2.04 individuals / ha), elevation of 1000 meters above the sea ( 2.68 individuals / ha), elevation of 1500 meters above the sea ( 0.89 individuals / ha) and the elevation of 2000 meters above the sea ( 0.12 individuals / ha).
\end{abstract}

Keywords: Density, Tarsius spectrum, Clabat Mountain, North Sulawesi.

\section{PENDAHULUAN}

Tarsius spectrum (nama sinonim: Tarsius tarsier) dalam bahasa lokal disebut tangkasi (Minahasa), ngasi (Sulawesi Tengah), Tanda bona passo (Wana), Podi (Tolaki), Wengu (Mornene) merupakan spesies primata endemik Sulawesi. Jenis ini merupakan satu dari beberapa spesies Tarsius di Sulawesi. Sampai sekarang teridentifikasi beberapa spesies, yaitu $T$. spectrum, Tarsius sangiriensis, Tarsius pumilis, Tarsius 
dentatus, Tarsius pelengensis, Tarsius laring, dan Tarsius sp (Shekelle, 2008).

Tangkasi merupakan salah satu primata terkecil dan beberapa diantara anggota spesiesnya merupakan satwa endemik Sulawesi yang terancam punah dan dilindungi. Tangkasi merupakan satwa yang dilindungi berdasarkan Undang-Undang No. 5/1990 dan Peraturan Pemerintah No. 7/1999. Menurut IUCN (2008), tarsius dalam Red Data Book IUCN (International Union for Conservation of Nature and Natural Resources) termasuk dalam kategori vulnerable (rentan).

Tangkasi mampu hidup di berbagai habitat, baik hutan primer maupun hutan sekunder. Meskipun memiliki sebaran habitat yang luas, kualitas habitat juga memegang peranan penting bagi kelestarian satwa liar pada umumnya, termasuk tangkasi. Berkurangnya luasan habitat karena berbagai sebab dan atau menurunnya daya dukung habitat akan meyebabkan terjadinya penurunan populasi satwa pada umumnya, termasuk tangkasi, baik secara langsung maupun tidak langsung. Sebaliknya, kualitas habitat yang baik akan mendukung seluruh aktivitas tangkasi termasuk perilaku reproduksi agar dapat berjalan dengan normal (Shekelle dan Leksono, 2004).

Sumber pakan dalam habitat juga merupakan salah satu faktor ekologi yang sangat menentukan kelestarian primata. Kualitas dan kuantitas pakan dapat berpengaruh pada perilaku dan organisasi sosial primata (Raemaker dan Chivers, 1980 dalam Bismark, 1994). Selain itu, pakan juga mempengaruhi luas daerah jelajah berhubungan dengan perilaku pergerakan primata di samping upaya pemenuhan sumber energi untuk pertumbuhan dan berkembang biak (Bismark, 1994).

Salah satu upaya yang perlu dilakukan untuk mempertahankan keberadaan tarsius di alam sebagai sumber keragaman hayati yaitu perlu dilakukannya konservasi sehingga populasinya di alam tidak terganggu. Hal ini sangat penting terutama untuk menjaga keseimbangan ekosistem seperti tercantum dalam Undang-Undang No. 5 tahun 1990 tentang Konservasi Sumber Daya Alam dan Ekosistemnya.

Masih minimnya informasi mengenai habitat ideal satwa endemik ini menjadi salah satu faktor penghambat upaya pelestariannya
(Bismark, 1994). Menurut BKSDA (2009), informasi tenang densitas tangkasi di Gunung Klabat belum diketahui. Gunung klabat merupakan gunung tertinggi di Provinsi Sulawesi Utara, dengan puncak ketinggiannya mencapai sekitar 2100 meter dpl.

Sehubungan dengan hal tersebut, maka perlu dilakukan penelitian tentang densitas tangkasi (Tarsius spectrum) pada elevasi yang berbeda di Gunung Klabat, Minahasa Utara. Salah satu lokasi yang menjadi habitat tangkasi ialah Gunung Klabat.

\section{METODE PENELITIAN Waktu dan Tempat Penelitian}

Penelitian dilaksanakan mulai Oktober sampai dengan Desember 2014 di Hutan Lindung Gunung Klabat, Kabupaten Minahasa Utara. Elevasi yang digunakan sebagai sampel lokasi penelitian ialah elevasi $500 \mathrm{mdpl}, 1000 \mathrm{mdpl}, 1500 \mathrm{mdpl}$, dan 2000 mdpl.

\section{Bahan dan Alat}

Bahan dan alat yang digunakan selama penelitian meliputi: alat penerima GPS, Thermohygrometer, alat kamera, alat tulis menulis, tali plastik, dan meteran.

\section{Metode Pengambilan Data}

Metode yang digunakan dalam penelitian ini ialah esimasi densitas tangkasi berdasarkan vokalisasi (Duet call). Pada setiap elevasi dibuat 10 plot yang berbentuk lingkaran dengan diameter $100 \mathrm{~m}$, dan jarak antar plot $200 \mathrm{~m}$ (Gambar 1). Setiap pagi hari ditentukan lokasi duet call pada satu plot dan penghitungan jumlah individu pada setiap duet call yang juga lokasi tempat tidur tangkasi dilakukan pada sore harinya. Metode yang sama juga dilakukan pada keseluruhan plot lainnya sehingga ke-40 plot selesai disurvai.

\section{Analisis Data}

Data diambil secara deskriptif dengan menghitung densitas tangkasi setiap elevasi yang berbeda. Dengan menggunakan rumus:

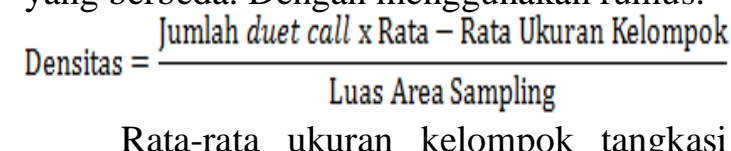
adalah 4,01 $\pm 1,83$ (Saroyo et al, 2014). 
Penghitungan densitas dilakukan pada setiap elevasi.



Gambar 1. Model plot lingkaran pada metode sampling

\section{HASIL DAN PEMBAHASAN \\ Metode Sampling Duet Call Berbentuk Lingkaran dengan Radius 100 m}

Luas pengambilan sampel sebesar 125,6 Ha, di mana total luas area tersebut mewakili $41,48 \%$ dari total area penelitian. Pengambilan data duet call dilakukan pada pagi hari pukul 05:00 sampai 06:00 dengan mencatat jumlah duet call.

Hasil pengamatan yang sudah dilaksanakan pada 40 plot disajikan pada Tabel 1. Dari tabel tersebut, urutan elevasi yang memiliki densitas paling rendah sampai paling tinggi ialah elevasi $2000 \mathrm{mdpl}, 1500$ mdpl, 500 mdpl dan 1000 mdpl.

Tabel 1. Hasil densitas tangkasi pada elevasi yang berbeda

\begin{tabular}{|c|c|c|}
\hline Elevasi & $\begin{array}{c}\text { Jumlah } \\
\text { Duet call }\end{array}$ & $\begin{array}{c}\text { Densitas } \\
\text { (Individu/Ha) }\end{array}$ \\
\hline $500 \mathrm{~m} \mathrm{dpl}$ & 16 & 2,04 \\
\hline $1000 \mathrm{~m} \mathrm{dpl}$ & 21 & 2,68 \\
\hline $1500 \mathrm{~m} \mathrm{dpl}$ & 7 & 0,89 \\
\hline $2000 \mathrm{~m} \mathrm{dpl}$ & 1 & 0,12 \\
\hline
\end{tabular}

Berdasarkan hasil penelitian, didapatkan bahwa jumlah duet call pada elevasi $500 \mathrm{mdpl}$ (16 duet call), elevasi 1000 mdpl (21 duet call), elevasi $1500 \mathrm{mdpl}$ (7 duet call) dan elevasi $2000 \mathrm{mdpl}$ (1 duet call). Duet call yang paling banyak terdengar yaitu pada elevasi $1000 \mathrm{mdpl}$ di mana terdapat 21 duet call, sedangkan yang paling sedikit yaitu pada elevasi $2000 \mathrm{mdpl}$. Hal ini disebabkan karena suhu mempengaruhi keberadaan tarsius dan juga terjadi gangguan dari aktivitas manusia (Gambar 2).



Gambar 2. Grafik densitas tangkasi pada elevasi yang berbeda

Pada seluruh plot didapatkan 45 lokasi duet call. Setiap duet call mewakili satu keluarga atau satu kelompok. Berdasarkan jumlah duet call tersebut didapati densitas individu sebesar 1,43 individu/ha. Dari hasil penghitungan pada seluruh lokasi duet call diperoleh jumlah total individu sebanyak 184 ekor, dengan komposisi kelompok umur yaitu dewasa 158 ekor, remaja 14 ekor, dan bayi 12 ekor.

Kepadatan populasi Tangkasi di Kawasan Gunung Klabat jauh lebih sedikit dibandingkan Tangkasi di Tangkoko Batuangus, Sulawesi Utara. Menurut Saroyo et al (2014), kepadatan populasi T. spectrum di Tangkoko Batuangus memiliki densitas individu sebesar 189 individu/km2. Rendahnya populasi tangkasi di Gunung Klabat pada saat penelitian diduga karena populasinya belum pulih akibat penebangan liar yang terjadi di dalam kawasan hutan Gunung Klabat, Minahasa Utara.

Waktu terjadinya duet call sangat bervariasi, mulai pukul 05:15 sampai 06:00. Durasi duet call terpendek yang tercatat selama penelitian yaitu selama 5 menit dan terpanjang selama 25 menit. Variasi waktu terjadinya duet call dipengaruhi oleh cuaca, luasan daerah jelajah dan gangguan predator.

Tangkasi keluar dari sarang sekitar jam 18:00 WITA saat akan mencari makan. Pada saat itu tangkasi mengeluarkan suara sebagai penanda teritori, dan hal yang sama terjadi ketika tangkasi akan kembali ke sarang. Selama penelitian, suara tangkasi lebih mudah dideteksi pada saat pagi hari 
sekitar jam 05:15 sampai 06:00 WITA, dibandingkan pada saat sore hari.

Tangkasi keluar dari sarang sekitar jam 18:00 WITA saat akan mencari makan. Pada saat itu tangkasi mengeluarkan suara sebagai penanda teritori, dan hal yang sama terjadi ketika tangkasi akan kembali ke sarang. Selama penelitian, suara tangkasi lebih mudah dideteksi pada saat pagi hari sekitar jam 05:15 sampai 06:00 WITA, dibandingkan pada saat sore hari.

Vegetasi merupakan salah satu komponen habitat yang memiliki arti penting bagi kehidupan harian tangkasi. Batang dan percabangan vegetasi digunakan tangkasi sebagai sarana untuk melakukan pergerakan harian, termasuk dalam mencari makan. Di samping itu, vegetasi yang beranekaragam turut menciptakan iklim mikro bagi kehidupan organisme lain termasuk serangga yang berpotensi sebagai pakan tangkasi.

Suhu mempunyai peranan penting pada setiap kehidupan satwa liar. Dimana suhu dapat mempengaruhi produktifitas satwa liar tersebut. Pada tangkasi, suhu yang tidak sesuai dapat memberikan dampak buruk bagi satwa tersebut (Gambar 3).

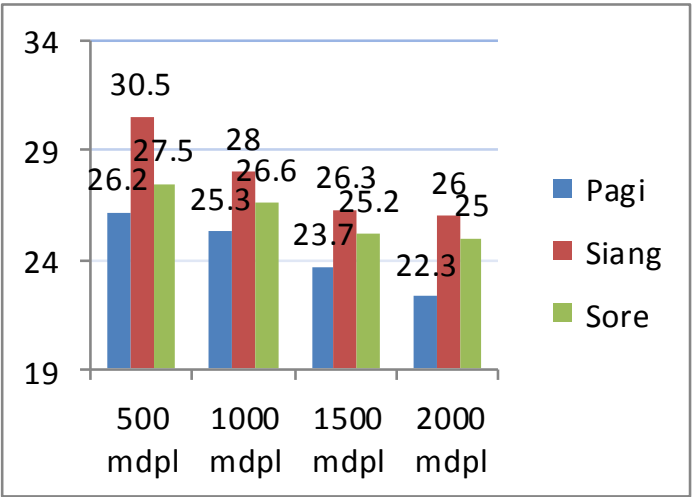

Gambar 3. Suhu udara habitat Tarsius spectrum pada setiap elevasi

Suhu yang didapat selama penelitian berkisar antara $22,3^{\circ} \mathrm{C}-30,5^{\circ} \mathrm{C}$. Suhu tertinggi didapati pada siang hari karena pada waktu siang terjadi cuaca yang sangat panas yang mengakibatkan suhu menjadi sangat tinggi. Sedangkan suhu terendah didapati pada pagi hari karena pada pagi hari dengan kondisi hutan yang sedang basah karena hujan dan embun mengakibatkan suhu menjadi sangat rendah.

\section{SIMPULAN DAN SARAN Simpulan}

Berdasarkan hasil pengamatan, densitas tangkasi pada elevasi $500 \mathrm{mdpl}(2,04$ individu/Ha), elevasi $1000 \mathrm{mdpl}(2,68$ individu/Ha), elevasi $1500 \mathrm{mdpl}(0,89$ individu/Ha) dan elevasi $2000 \mathrm{mdpl}(0,12$ individu/Ha). Duet call tangkasi (Tarsius spectrum) dapat dimanfaatkan sebagai alat untuk estimasi densitas menggunakan metode sampling sistematis dengan plot berbentuk lingkaran.

\section{Saran}

- Perlu dilakukan penelitian lebih lanjut untuk menentukan densitas yang lebih tepat.

- Distribusi tangkasi juga mencakup daerah-daerah pertanian dan kebun terutama pada rumpun-rumpun bambu, sehingga penelitian populasi tangkasi sebaiknya juga dilakukan di habitat tersebut.

\section{DAFTAR PUSTAKA}

Bismark, M. (1994). Ekologi makan dan perilaku bekantan (Nasalis larvatus Wurmb.) di hutan bakau Taman Nasional Kutai, Kalimantan Timur. (Disertasi Program Pasca Sarjana). Institut Pertanian Bogor, Bogor.

Saroyo, Koneri, K., Siahaan, R., Tallei, T.E., Kiroh, H.J., and Repi, T. 2014. Density of Tangkasi (Tarsius spectrum) Population and Development of Population Estimation Method Based on Duet Call at Tangkoko-Batuangus Nature Reserve, North Sulawesi. Current Research Jurnal of Biological Sciences.

Shekelle, M. 2008. Distribution and Biogeography of Tarsiers. In Primates of the Oriental Night. Indonesian Institute of Sciences Research Center for Biology. Cibinong

Shekelle M dan Leksono MS. 2004. Strategi Konservasi di Pulau Sulawesi dengan Menggunakan Tarsius sebagai Flagship Spesies. Biota Vol. IX (1): 1-10, ISSN 0853-8670. 